\title{
Introduction to the Minitrack on Trust, Identity, and Trusted Systems in Digital Environments
}

\author{
Sirkka L. Jarvenpaa \\ The University of Texas at Austin \\ Sirkka.jarvenpaa@mccombs.texas.edu
}

\begin{abstract}
Within the 51th Hawaiian International Conference on System Sciences (HICSS), we organize for the second time a minitrack on Trust, Identity, and Trusted Systems in Digital Environments. Trust is a pervasive concern not just with new technologies but also with established technologies as they become more complex and interdependent. Through four papers, the track will discuss and debate when and to what degree trust matters, in what form(s), and with which consequences in the context of software code, cognitive assistants, the sharing economy, and sustainable product information.
\end{abstract}

\section{Introduction}

Questions abound as trust is a pervasive concern not just with new technologies but also with established technologies as they become more complex and interdependent. For example, on a higher level how do new advancements in both hardware and software technologies change the way we view interpersonal trust, trust in collectives, institutional trust, trust in technology, and trust in processes, and how do these different forms of trust interact? Furthermore, what are the implications for trust as technologies take on capabilities with both social and moral agency?

Technology responds to our actions and talks back to us and is associated with provisional and consequential actions. As systems become more human like, they might exacerbate rather than compensate weaknesses common in trust assessments among humans. Some technologies are argued to even replace the trust we now have in institutions as trust shifts from humans and central organizations to networks of computers and decentralized anonymous organizations that have no geographic boundaries. What are the risks and vulnerabilities with these emerging algorithmic capabilities and highly distributed peer-to-peer systems?

\author{
Robin Teigland \\ Stockholm School of Economics \\ robin.teigland@hhs.se
}

While there are endless issues to discuss when it comes to trust, this track will attempt to shed some light on the larger issues such as when and to what degree trust matters, in what form $(s)$, and with which consequences, through four papers.

In the first paper, "Trustworthiness Perceptions of Computer Code: A Heuristic-Systematic Processing Model", the authors Gene Alarcon and Tyler Ryan develop a theoretical framework for assessing the use and reuse of software code. The authors report that it is estimated that today $80-90 \%$ of code has been reused within not only the same project but also across multiple software projects. Building on a heuristicsystematic model of persuasion, the authors propose a model describing a five-step process of how programmers perceive the trustworthiness of computer code.

In the second paper, we move from trust in computer code by programmers to trust in cognitive assistants (CAs) by people. In their paper, "Towards a Framework of Trust Determinants in People and Cognitive Assistants Interactions", the authors Md. Abul Kalam Siddike and Youji Kohda compare CAs, e.g. Siri, Watson, with previous emerging technologies, e.g., steam engines, and state that in order for such technologies to be adopted by society, they need to be trusted by people. As such the authors develop a framework to measure people's trust in using CAs, in which reliability, attractiveness, and emotional attachments are influential factors for generating trust.

In the third paper, "Trust and Distrust in Two-sided Markets: An Example in the Sharing Economy" by Christoph Mittendorf, we turn to the sharing economy. Using the setting of 'BlaBlaCar', a popular ridesharing platform spreading throughout Europe and even to Mexico and India, the author investigates the implications of 'trust' and 'distrust' in the sharing platform as well as 'trust' and 'distrust' in the third parties sharing through the platform on the users' intention to engage in a sharing encounter. 
Finally, the fourth paper, "Understanding the Intention to Trust Product Information and Certifications to Promote Sustainable Consumption: Applying the Theory of Planned Behavior", is written by Djoko Sayogo, Jing Zhang, Sergio Picazo-Vela, Babak Bahaddin, and Luis Luna-Reyes. The authors use a convenience sample of students in Mexico, Indonesia, and the USA to test a model of consumer trust in sustainable product and certification information included in the product's package and label by using Azjen's theory of planned behavior as a framework.

While the four papers provide a variety of research purposes and contexts, there is an ever growing number of research questions related to trust. Below we list some further areas that we hope may provide some inspiration for scholars to investigate within this fascinating area.

- Understanding issues of trust and reputation in the context of sharing economy organizations, e.g., in the platform provider, among the users of the platform, in the organization behind the platform, in financial transactions conducted through the platform.

- Understanding the relationship between trust in an organization and an organization's handling of its users' data, e.g., privacy/integrity, security, use of the cloud.

- Understanding the relationship between trust in an organization and trust in the organization's technology-based offerings.

- Understanding how regulation and policy at the national and international levels influence issues of trust and technology penetration, e.g., in the financial industry and the sharing economy, and vice versa.

- Understanding the role of trust between users and emerging technologies, e.g., personal robots, smart toys, wearables, 3D printing, augmented reality, virtual reality, autonomous vehicles, drones, AIenabled products and services.

- Understanding the role of trust in the development of algorithms, e.g., functions, openness of coding, data collection.

- Understanding the activities and narratives that startup organizations in emerging high-technology industries use to build trust and legitimacy in the industry, e.g., users/consumers, incumbents, regulators.

- Understanding the relationship between trust and business models in startups within emerging industries as well as in the commercialization of new technologies by established firms.

- Understanding the relationship between trust and the development and dynamics of self-regulated, decentralized, peer-to-peer networks.

- Understanding the relationships among trust, technology affordances, and institutional logics.

- Understanding the relationship between national culture and institutions and trust in technology and digital environments that know no geographic boundaries.

- Understanding the relationship between trust and control in digital environments.

- Understanding how trust is built, maintained, and repaired when the context is continuously changing. 